\title{
GESTÃO ESTRATÉGICA DE PESSOAS, ESTRATÉGIA DE RETENÇÃO DE PROFISSIONAIS E COMPROMETIMENTO ORGANIZACIONAL EM UMA ESTRUTURA ORGANIZACIONAL REMOTA*
}

\author{
STRATEGIC MANAGEMENT OF PEOPLE, \\ RETENTION STRATEGY OF PROFESSIONALS AND \\ ORGANIZATIONAL COMMITMENT IN A REMOTE \\ ORGANIZATIONAL STRUCTURE
}

Recebido $13 / 11 / 2012$

Aceito $01 / 06 / 2013$

Nildes Raimunda Pitombo Leite ${ }^{1}$ Lindolfo Galvão de Albuquerque ${ }^{2}$

\section{RESUMO}

O principal objetivo deste artigo é analisar as características da gestão estratégica de pessoas, da estratégia de retenção de profissionais e de obtenção do comprometimento organizacional, tomando-se por base o caso Caulim da Amazônia S.A. - CADAM/Pará Pigmentos S.A. - PPSA e buscando-se responder à questão: quais as características da gestão estratégica de pessoas, com foco na estratégia de retenção de profissionais e de obtenção do comprometimento organizacional em suas peculiaridades de estruturas organizacionais remotas? Os sujeitos da pesquisa são diretores, gerentes, profissionais de $\mathrm{RH}$, supervisores e coordenadores das unidades de Ipixuna, Monte Dourado e Barcarena, localizadas na Região Norte do Brasil, perfazendo um total de trinta e seis entrevistados. Os resultados mostram, nas interfaces das três unidades, traços que unem as pessoas, em todas essas localidades e em torno do mesmo propósito: reter profissionais de talento. Pode-se dizer que, se torna possível identificar as peculiaridades que conduzem ao comprometimento das pessoas com os objetivos organizacionais, nessas estruturas organizacionais, a partir da abordagem estratégica da gestão de pessoas. A retenção de profissionais está condicionada à capacidade de adaptação desses profissionais ou de seus familiares nessas regiões.

Palavras-chave: Gestão Estratégica de Pessoas. Estratégia de Retenção de Profissionais. Comprometimento Organizacional. Estrutura Organizacional Remota.

\footnotetext{
* Este trabalho é parte de pesquisa mais ampla, apoiada pela FAPESP - Fundação de Amparo à Pesquisa do Estado de São Paulo

${ }^{1}$ Possui graduação em Administração pela Escola de Administração de Empresas da Bahia, especialização em Administração de Recursos Humanos pela Faculdade de Ciências Administrativas e Contábeis da UMA, mestrado em Administração pela Universidade Federal da Bahia - UFBA, doutorado e pós-doutorado em Administração pela Universidade de São Paulo - USP. Atualmente é professora na Universidade Nove de Julho - UNINOVE. São Paulo, São Paulo, Brasil. E-mail: nildespitombo@consensopg.com.br.

${ }^{2}$ Possui graduação, mestrado e doutorado em Administração pela Universidade de São Paulo - USP. Atualmente é professor titular da Universidade de São Paulo - USP. São Paulo, São Paulo, Brasil. E-mail: Igdalbuq@usp.br.
} 


\section{ABSTRACT}

The main objective of this paper is to analyze the characteristics of the strategic people management, the strategy of retention of professional and of obtaining of organizational commitment, by taking up basis the case of Caulim da Amazônia S.A. - CADAM/Pará Pigmentos S.A. - PPSA and seeking to answer the question: what are the characteristics of the strategic management of people, focusing on retention strategy of professional and obtaining of organizational commitment in their peculiarities of remote organizational structure? The research subjects are directors, managers, HR professionals, supervisors and coordinators of units Ipixuna, Monte Dourado and Barcarena, located in northern region of Brazil, for a total of thirty-six respondents. The results show, at the interfaces of the three units, traits that unite people in all these places and around the same purpose: to retain talented professionals. One could say that, it becomes possible to identify the peculiarities that leads to commitment of people with the organizational objectives, these organizational structures, from the strategic approach of people management. The retention of professionals is conditioned on adaptive capacity of these professionals and their families in these regions.

Keywords: Strategic Management of People. Retention Strategy of Professionals. Organizational Commitment. Organizational Structure Remote.

\section{INTRODUÇÃO}

Na literatura contemporânea, a exemplo dos trabalhos de Mascarenhas (2008) e Lepak e Shaw (2008), verifica-se o evidenciamento da sucessão de teorias, críticas e proposições em gestão estratégica de pessoas, quer abordando-a como alinhamento sistêmico, como potencial competitivo ou em seus temas contemporâneos, tais como: gestão de competências, individual e organizacional, estratégicas para a organização; gestão de mudanças, delineando um modelo de gestão compatível com uma visão dialética da organização; gestão e avaliação de resultados em gestão de pessoas ou a necessidade de acompanhamento, mensuração e avaliação do impacto das práticas de $\mathrm{RH}$ no desempenho organizacional; gestão da diversidade; aprendizagem organizacional; organização pluralista; sistemas de informação em gestão de pessoas e sua contribuição para a estruturação da gestão estratégica de pessoas.

As ideias iniciais acerca da gestão estratégica de pessoas remontam à década de 1920, nos Estados Unidos, nas quais, políticas e práticas de gestão de pessoas eram debatidas por economistas e acadêmicos das relações industriais, conforme indicado por Lengnick-Hall; Lengnick-Hall; Andrad e Drake (2009). Nesse período, apenas uma pequena parte das organizações formulou e adotou, conscientemente, práticas inovadoras de gestão, as quais representavam uma abordagem estratégica. Grande parte das organizações operou, até cerca de trinta anos atrás, dentro da orientação micro, quando, então, começou a despertar para a perspectiva macro e para a propagação do conceito de gestão estratégica de pessoas.

Neste artigo, é contemplada a perspectiva macro e orientação estratégica da gestão de pessoas, reiterando-se o nível organizacional escolhido para análise, respaldadas nas abordagens teóricas de gestão estratégica de pessoas: universalista, contingencial, configuracional e cultural, tomando-se por referências, estudiosos como Mascarenhas (2008); Lacombe e Albuquerque (2008); Martín-Alcázar, Romeo-Fernández e Sánchez-Gardey (2008); Lepak e Shaw (2008); Lengnick-Hall; Lengnick-Hall; Andrade e Drake (2009).

O objetivo primordial deste artigo é analisar as características da gestão estratégica de pessoas, da estratégia de retenção de profissionais e de obtenção do comprometimento organizacional, tomando-se por base o caso CADAM/PPSA e buscando-se responder à questão de pesquisa: quais as características da gestão estratégica de pessoas na CADAM/PPSA, considerando- 
se a estratégia de retenção de profissionais e de obtenção do comprometimento organizacional em suas peculiaridades de estruturas organizacionais remotas?

As organizações CADAM/PPSA, estão inseridas em uma estrutura organizacional remota, confinada e isolada dos grandes centros urbanos, em toda a plenitude de suas peculiaridades. O conceito de estrutura organizacional remota (departamentalização e atribuições), apresentado por Leite (2008), envolve situações em que a organização cria uma infra-estrutura necessária à instalação das pessoas em uma dada região distante dos grandes centros urbanos para operar suas unidades lá instaladas. Essa infra-estrutura pode compreender: obras rodoviárias, usina hidrelétrica, atividades de pecuária, agronomia, construção de hotel, residências, farmácia, cinema, escola, detenção, desenvolvimento de comércios e pequenas indústrias, que venham dar sustentação à coletividade para lá transferida. As instalações de unidades remotas exigem análise acurada para que as decisões sejam tomadas se levando em consideração os fatores envolvidos que podem vir a afetar: a forma de gerir as pessoas; a estratégia de retenção de profissionais; o comprometimento desses profissionais com as organizações.

Uma breve fundamentação teórica subsidiou o roteiro de entrevistas, assim como a discussão dos resultados nele encontrados, em suas categorias de análise: gestão estratégica de pessoas, estratégia de retenção de profissionais e comprometimento organizacional.

\section{GESTÃO ESTRATÉGICA DE PESSOAS, ESTRATÉGIA DE RETENÇÃO DE PROFISSIONAIS E COMPROMETIMENTO ORGANIZACIONAL}

As décadas de 1960, 1970 e 1980 testemunharam mudanças profundas no papel de recursos humanos e na visão gerencial da função de RH como administrativa e profissional tão-somente. A década de 1990 trouxe nova ênfase sobre estratégia de negócios e a importância dos sistemas de $\mathrm{RH}$, inclusive com discussões acerca das denominações fator humano e gestão de pessoas sob a perspectiva estratégica (ULRICH, 1998; ALBUQUERQUE, 1999). A década de 2000 vem perenizando espaços para mais reflexões acerca: da gestão estratégica de pessoas (ULRICH, 2000; WRIGHT, DUNFORD, SNELL, 2001; WRIGHT, SNELL, 2001; BECKER, HUSELID, ULRICH, 2001; HANASHIRO, TEIXEIRA, ZACCARELLI, 2007; ULRICH, ULRICH, 2011; ULRICH, ALLEN, BROCKBANK, YOUNGER, NYMAN, 2011); da estratégia de retenção de profissionais (CHEW, 2004; FRIEDMAN, 2007); do comprometimento organizacional (MEYER, STANLEY, HERSCOVITCH, TOPOLNYTSKY, 2002; MOYNIHAN, PANDEY, 2007; SOLINGER, OLFFEN, ROE, 2008; BASTOS, SIQUEIRA, MEDEIROS, MENEZES, 2008).

A estratégia de gestão de pessoas descreve a orientação da organização, no que se refere à gestão do fator humano. Para tanto, proporciona coesão ao conjunto de práticas, por meio das quais essa gestão é fomentada. Por sua vez, as políticas descrevem a coordenação dessas práticas, com vistas ao alcance dos objetivos ligados à força de trabalho, conforme Martin-Alcázar; RomeroFernández; Sanchez-Gardey (2005).

A gestão estratégica de pessoas, contemplada como alinhamento sistêmico, depara-se com as abordagens contingencial, universalista, configuracional e cultural. A atuação do RH passa a ser questionada, com vistas à transformação necessária para a incorporação da estratégia. Por sua vez, a atuação estratégica do RH toma como ponto de partida o diagnóstico das condições de negócio, incorporando a ideia do planejamento estratégico de pessoas, com a responsabilidade de articulação com o processo de planejamento estratégico corporativo.

A abordagem contingencial considera a necessidade de alinhamento da gestão de pessoas a fatores de contingência, tais como ambiente externo, estratégia e cultura organizacional, 
atribuindo-se, entretanto, uma condição passiva e uma direção linear de adequação do modelo de gestão de pessoas a esses fatores. A universalista assume a existência de práticas de gestão de pessoas cuja adoção estaria diretamente relacionada a níveis superiores de desempenho organizacional. A configuracional reconhece a importância do alinhamento organizacional horizontal e visualiza a cultura organizacional em toda a sua relevância, de acordo com Paschini (2006). A abordagem cultural pressupõe a existência de significados e valores compartilhados, o envolvimento moral e as manifestações culturais dos grupos para a compreensão de sua situação na organização.

Contemplada como potencial competitivo a gestão estratégica de pessoas se volta para uma reconceitualização do modelo de gestão estratégica de pessoas, revigorando-se a ênfase em comportamentos, competências, alinhamento estratégico, flexibilidade organizacional, cultura organizacional, diversidade cultural. Essa ênfase sugere que a direção do diálogo está voltada para a necessidade de repensar a estrutura e as funções estratégicas da área de gestão de pessoas, como pode ser verificado em Mascarenhas (2008).

Como parte do escopo em seus temas contemporâneos, a gestão estratégica de pessoas trata de questões referentes à: inovação conectada à gestão de pessoas; gestão do terceiro setor; governança corporativa; transformações no mercado de trabalho; gestão para a sucessão de profissionais; internacionalização das organizações; gestão estratégica de carreira; avaliação de resultados organizacionais em gestão de pessoas, confome pode ser visto em Albuquerque e Leite (2009), Mascarenhas (2008), Lacombe e Albuquerque (2008). Martín-Alcazár, Romero-Fernandez e Sanches-Gardey (2008) reiteraram a gestão de pessoas abrangendo políticas, práticas e filosofias globais, envolvendo a força de trabalho e as questões sociais, constituintes dos elementos centrais da estratégia.

Mascarenhas (2008) salientou que os primórdios da gestão estratégica de pessoas estão associados ao paradigma de adequação indivíduo-cargo, o qual remete aos princípios difundidos pela teoria clássica da administração. Tal paradigma se restringia à busca do alinhamento entre as tarefas, de responsabilidade de determinadas posições hierárquicas, e às qualificações e características necessárias das pessoas que ocupariam esses cargos. O autor trouxe, ainda, as críticas - conceitual, empírica, cultural e prescritiva - aos pressupostos, conceitos e práticas associadas às proposições pioneiras de gestão estratégica de pessoas, nas quais são apontadas, respectivamente, as limitações conceituais, as dúvidas sobre efetividade empírica, as dificuldades práticas e a introdução de novos conceitos para a compreensão da evolução da gestão estratégica de pessoas.

Decorrentes de tais restrições, várias críticas surgiram, dentre elas as oriundas da escola das relações humanas, que percebia a organização como um sistema social complexo, cujas interações extrapolavam as posições formais. Graças à incorporação de tais críticas, a gestão estratégica de pessoas segue seu curso de desenvolvimento e se associa à noção de alinhamento sistêmico, evidenciando e popularizando o papel da gestão de pessoas para o alcance dos objetivos estratégicos da organização.

Ao mesmo tempo, mudanças tecnológicas, globalização da economia, acirramento da competição entre organizações e entre países e diversidade da força de trabalho são alguns fatores que influenciam significativamente a gestão das organizações. Tais fatores têm exigido que essas organizações se tornem capazes de captar, reter e desenvolver profissionais aptos a adaptar-se às exigências do meio no qual atuam. Ulrich (1998) já considerava que as organizações bem-sucedidas são aquelas que conseguem atrair, reter e desenvolver profissionais responsáveis tanto por clientes, quanto pelo gerenciamento de crescentes oportunidades tecnológicas. No que tange à gestão estratégica de pessoas e à estratégia de retenção de profissionais em estruturas organizacionais localizadas fora dos grandes centros urbanos, encontram-se os estudos de Leite e Albuquerque (2009 a), (2009 b) e (2009 c). 
Com esse curso de desenvolvimento da gestão estratégica de pessas, a estratégia de retenção de trabalhadores altamente qualificados está entre as formas mais comuns que os profissionais da área podem planejar para responder a essas mudanças, conforme salientado por Friedman (2007). Em seu estudo sobre a estratégia de retenção de profissionais, Chew (2004) agrupou dois conjuntos de fatores que favorecem a prática de retenção de funcionários centrais de organizações australianas: fatores de gestão de pessoas (ajuste entre pessoas e organização, remuneração, reconhecimento e recompensa, treinamento e desenvolvimento de carreira, oportunidades desafiadoras de trabalho); fatores organizacionais (atitude da liderança, políticas e cultura da organização, relacionamento entre integrantes da equipe de trabalho e ambiente de trabalho satisfatório).

Essa estratégia pode ser associada ao comprometimento organizacional, considerado por Robbins (2005) como terceira atitude crescente, antecedido de envolvimento e participação, assim justificado: um indivíduo só pode se envolver em seu trabalho quando participa ativamente dele, se identifica psicologicamente com ele e considera o seu desempenho como algo valioso para si; o indivíduo só está apto a comprometer-se quando se identifica com uma organização e com os seus objetivos, desejando manter-se parte dessa organização.

Do ponto de vista dos atores organizacionais, o comprometimento organizacional é esperado por seu impacto em variáveis desejáveis e, partindo desse pressuposto, muitas pesquisas foram conduzidas nas últimas décadas para avaliar quais variáveis contribuem para o desenvolvimento desse vínculo, e que consequências são esperadas com o seu estabelecimento. A consolidação de estudos que o abrangem o destacou como conceito mais desejável e esperado do que construtos antes predominantes nas pesquisas de comportamento organizacional, a exemplo de motivação e satisfação. Entretanto, pesquisadores como Falkenburg e Schyns (2007) reportaram questionamentos que situam a satisfação como um consequente do comprometimento, como um antecedente, ou mesmo como uma variável mediadora de sua relação com outros antecedentes; Moynihan e Pandey (2007) examinaram os efeitos dos atributos individuais, características do trabalho e variáveis organizacionais em três aspectos, considerados dimensões da motivação com o trabalho: satisfação com o trabalho, envolvimento com o trabalho e comprometimento organizacional.

Foi sugerida a existência de uma lacuna na agenda de pesquisa do comprometimento organizacional, além dos problemas apresentados pela base instrumental e das evidências de sobreposição da base normativa à base afetiva (MEYER, STANLEY, et al., 2002), o que levou estudos recentes, a exemplo de Solinger et al., (2008) a propor um retorno do conceito de comprometimento à definição unidimensional apresentada inicialmente por Mowday et al. (1982).

Com base nos sentidos psicológico e filosófico do comprometimento pessoal, Rogers (1977) atribuiu uma direção organísmica total, uma realização, espécie de direção, plena de propósito e de significado. Em Polanyi (1958 apud Abbagnano, 2003), filósofo da ciência, enfatizou que o comprometimento pessoal profundo é a única base sobre a qual pode a ciência se manter, já que, pela ciência e sob todos os seus aspectos, perpassa o comprometimento pessoal, disciplinado.

Juntem-se a isso as visões de Dessler (1996), quando enfatizou que a forma mais poderosa de garantir a execução correta do trabalho de uma organização é sincronizar as suas metas com as de seus funcionários. Isso equivale dizer, em outras palavras, que criar comprometimento, dentro de tal organização, significa forjar a síntese do comprometimento pessoal/organizacional que, por sua vez, implica facilitar a gestão estratégica das pessoas e incrementar a estratégia de retenção de profissionais. Bastos, Siqueira, Medeiros e Menezes (2008) assinalaram a vertente que destaca a necessidade de trabalhar o comprometimento a partir de indicadores comportamentais ou de processos que vinculem o sujeito a um curso específico de ação; Salancik (1977), que enumerou três elementos fundamentais para gerar comprometimento: a volição, a 
visibilidade e a irreversibilidade das ações, na medida em que esses elementos estão na base do sentimento de responsabilidade com o curso da ação escolhido.

\section{ASPECTOS METODOLÓGICOS DA PESQUISA}

Na primeira fase desta pesquisa se realizou um levantamento bibliográfico para a construção dos roteiros de entrevista e de observação, bem com a fundamentação teórica pertinente ao objetivo e à questão de pesquisa. O nível proposto de análise foi o organizacional. Como critério de escolha do universo tomou-se por base a estrutura organizacional remota. A Caulim da Amazônia S.A. - CADAM/Pará Pigmentos S.A. - PPSA - aqui tomadas como unidades de análise, operam com estrutura considerada remota, confinada e isolada, localizadas em Ipixuna, Monte Dourado e Barcarena, sendo essa última, uma unidade semiremota.

Na segunda fase realizou-se o estudo de campo com vistas a responder à questão de pesquisa, contemplando diretores, gerentes, profissionais de $\mathrm{RH}$, supervisores e coordenadores das unidades de Ipixuna, Monte Dourado e Barcarena, perfazendo um total de trinta e seis entrevistados. Assim, os dados primários foram coletados por meio de entrevistas em profundidade e observações sistemáticas nas áreas operacionais e assistemáticas em visitas aos locais das entrevistas; os dados secundários foram obtidos por meio de análise de documentos fornecidos pelas empresas e sites.

Tal estudo de campo está inserido no contexto da pesquisa qualitativa, privilegiando-se as premissas de Mattos (2006) acerca da questão de generalização. Foi utilizada a estratégia de estudo de caso com as bases dos estudos de Gil (2009); Eisenhard e Graebner (2007); Yin (2005); Cooper e Schindler (2003); Eisenhard (1989). Utilizaram-se, no tratamento de dados: análise de conteúdo, com base em Bardin (2009) e Selltiz, Wrightsman e Cook (2005); metodologia reflexiva, de acordo com Vergara (2005), segundo a qual, fundamentação teórica e coleta de dados empíricos caminham conjuntamente; análise documental das especificidades de cada uma das três unidades investigadas. Nesta pesquisa, a análise de conteúdo das entrevistas apoiou-se, predominantemente, em procedimentos interpretativos, assim como a metodologia reflexiva foi utilizada para a interpretação dos dados empíricos oriundos das entrevistas e observações, bem como para a interpretação dos pressupostos teóricos que respaldaram a pesquisa empírica.

\section{O ESTUDO DE CASO}

A Caulim da Amazônia S.A. - CADAM e a Pará Pigmentos S.A. - PPSA fornecem caulins finos e delaminados para a indústria mundial de papéis e cartões revestidos. A CADAM é produtora e exportadora de caulim para revestimento de papéis e cartões do Brasil e tem suas operações de mineração, industrialização e embarque localizadas às margens do rio Jari, divisa dos Estados do Pará e Amapá, na Região Norte. A empresa iniciou suas atividades em 1971, tendo passado à esfera da CAEMI em 1991. A CADAM tem significativas vantagens competitivas: excelência operacional, logística privilegiada e grande volume de reservas. Suas vendas representam cerca de $9 \%$ do mercado mundial de caulim para revestimento de papel. A empresa possui instalações no Brasil e na Bélgica e mina própria situada no Norte do Brasil, com qualidades reconhecidas internacionalmente.

A Pará Pigmentos é uma organização brasileira produtora de pigmentos à base de caulim, com estrutura operacional integrada, que engloba as atividades de mineração, industrialização e embarque. Deu início às suas operações em 1996. A PPSA também é suportada por jazidas de classe mundial, em termos de qualidade, tamanho e flexibilidade, localizadas na bacia do Rio Capim, no Norte do Brasil. 
Com estrutura comercial própria nos principais mercados do mundo, CADAM e PPSA ocupam posições de destaque no cenário internacional, atendendo aos maiores grupos papeleiros mundiais, devido à qualidade dos seus produtos e à logística diferenciada que permite a regularidade no fornecimento. Em seus documentos encontra-se o registro de modelo de gestão que busca fazer mais e melhor pelo meio-ambiente, usando os recursos naturais de forma sustentável, gerando menos resíduos, valorizando e trabalhando a educação ambiental dentro e fora da empresa.

CADAM e Pará Pigmentos, companhias de mineração, beneficiamento e comercialização de caulim para os mercados externo e interno têm como política de gestão os seguintes princípios: "atender à legislação e normas aplicáveis às suas atividades e aos seus produtos e serviços; cumprir os compromissos assumidos com clientes, acionistas, colaboradores, fornecedores, órgãos governamentais e comunidades; aumentar a competitividade através do aprimoramento dos processos, visando à qualidade do produto, à prevenção da poluição, dos impactos ambientais e dos riscos ocupacionais de seus colaboradores diretos e indiretos; promover o desenvolvimento e a capacitação dos colaboradores; monitorar o sistema de gestão, através do estabelecimento de objetivos e metas para melhorias contínuas e acompanhamento permanente de seu cumprimento". Seus valores envolvem: proteção ao meio-ambiente; promoção da saúde e segurança dos empregados e familiares; respeito e promoção do bem-estar das populações vizinhas; postura ética e cidadã através da transparência das intenções e ações com a sociedade; qualidade. Seu Sistema Integrado de Melhorias - SIM é para a empresa inteira e representa "uma forma de agir que busca a mudança de comportamento das pessoas".

A Unidade Ipixuna está situada em Ipixuna, município brasileiro localizado no nordeste do Estado do Pará. Essa unidade é considerada remota, isolada e confinada. Sua atividade de extração de caulim dá-se em mina a céu aberto. Seu acesso ocorre por estrada de caulim, com travessia de balsa pelo rio Capim. Não existe núcleo residencial, onde os funcionários vivam com as suas famílias. Existem os alojamentos gerenciais, administrativos e operacionais. A infra-estrutura desses alojamentos é considerada adequada, com espaços para lazer, exercícios físicos, alimentação e descanso, além de caminhadas em contato com a natureza. $O$ turno de trabalho do grupo administrativo é normal e as pessoas podem se deslocar para suas casas aos finais de semana, se desejarem. $O$ turno do grupo operacional obedece ao regime de $15 \times 15$, no qual eles ficam quinze dias consecutivos nos alojamentos e quinze dias de folga, com os familiares em seus locais de origem.

A Unidade Monte Dourado, situada às margens do rio Jari, divisa dos Estados do Pará e Amapá, Região Norte, localiza-se em Monte Dourado, com o terminal Munguba. Monte Dourado dista $95 \mathrm{~km}$ ao Sul da Linha do Equador. É distrito do município de Almeirim, Pará, situado às margens do rio Amazonas. Cerca de 600 km de Monte Dourado, em terras do Pará, encontra-se o Parque Indígena Tumucumaque, onde vivem três mil índios da tribo Aparaís, descendentes de Tupis. Foi criado o núcleo residencial, onde os funcionários residem com as suas famílias. Monte Dourado é considerada uma unidade remota isolada e confinada. Seu acesso dá-se pelo rio Jari e pelo aeroporto da Jari Celulose. Sua atividade de extração de caulim acontece em mina a céu aberto.

A Unidade Barcarena - Finalização e Embarque, localiza-se na antiga aldeia dos índios Aruãs. O município de Barcarena pertence à mesorregião Metropolitana de Belém e à microrregião de Belém. É um importante pólo industrial, onde é feita a industrialização, beneficiamento e exportação de caulim, alumina, alumínio e cabos para transmissão de energia elétrica. Inicialmente as residências foram construídas na Vila dos Cabanos, a qual teve sua infra-estrutura criada e administrada pela ALBRAS. A ALUNORTE foi responsável pela ampliação e pela adaptação à realidade da época. Essa Vila foi entregue posteriormente para a Prefeitura administrar. É uma Unidade, considerada semi-remota, não isolada e não confinada, fica localizada próxima à 
vila residencial dos Cabanos e dista, aproximadamente, 40 quilômetros de Belém. Por cuidar da finalização e do embarque das unidades de Ipixuna e Monte Dourado ela também fez parte da pesquisa. Seu acesso é possibilitado por balsa ou estrada asfaltada. A exportação do caulim é feita por essa Unidade, no Porto de Conde.

Na tabela 1 são apresentados os dados para a análise de conteúdo das trinta e seis entrevistas realizadas na CADAM/Pará Pigmentos, em que as unidades de codificação, representadas por palavras-tema e respaldadas por palavras-chave ou frases-chave, foram tomadas de segmentos do conteúdo das entrevistas constituídos de significação para o objetivo desta pesquisa. $O$ agrupamento foi feito observando-se a sequência na qual pudessem ser contempladas as categorias de análise desta pesquisa, quais sejam: gestão estratégica de pessoas, estratégia de retenção de profissionais e comprometimento organizacional. Do mesmo modo, foi realizado o reagrupamento das palavras-chave ou frases-chave que melhor representassem as quinze palavras-tema, denominadas unidades de codificação. Para mostrar a presença ou ausência dessas palavras ou frases escolheu-se, auxiliarmente, fazer a contagem do número de vezes em que elas estiveram presentes ou ausentes, sem contar a ocorrência das repetições delas no conteúdo de uma mesma entrevista.

\begin{tabular}{|c|c|c|c|c|c|c|c|}
\hline \multicolumn{8}{|c|}{$\begin{array}{l}\text { APRESENTAÇÃO DOS DADOS PARA A ANÁLISE DE CONTEÚDO } \\
\text { UNIDADES: IPIXUNA (I) MONTE DOURADO (MD) E BARCARENA (B) }\end{array}$} \\
\hline \multirow{3}{*}{$\begin{array}{l}\text { Unidades de Codificação } \\
\text { Palavras-tema }\end{array}$} & \multirow{3}{*}{ Palavras-chave ou Frases-chave } & \multicolumn{6}{|c|}{ Contagem } \\
\hline & & \multicolumn{3}{|c|}{ Presença } & \multicolumn{3}{|c|}{ Ausência } \\
\hline & & $\mathbf{I}$ & MD & B & $\mathbf{I}$ & MD & B \\
\hline 1. Valorização & $\begin{array}{l}\text { Evidência da valorização de opiniões e descober- } \\
\text { tas em relação à maneira de se obter resultados; } \\
\text { Evidência da valorização do trabalho. }\end{array}$ & 14 & 09 & 07 & 02 & 03 & 01 \\
\hline $\begin{array}{l}\text { 2. Aprendizagem / Rea- } \\
\text { prendizagem }\end{array}$ & $\begin{array}{l}\text { Reconhecimento da necessidade de apren-diza- } \\
\text { gem/reaprendizagem em relação ao trabalho. }\end{array}$ & 09 & 11 & 06 & 07 & 01 & 02 \\
\hline 3. Desenvolvimento & $\begin{array}{l}\text { Demonstração do estímulo ao desenvolvimento } \\
\text { pessoal e profissional na própria organização. }\end{array}$ & 09 & 10 & 06 & 07 & 02 & 02 \\
\hline 4. Incentivos & $\begin{array}{l}\text { Disponibilização de incentivos vinculados a resul- } \\
\text { tados obtidos pela equipe. }\end{array}$ & 08 & 08 & 04 & 08 & 04 & 04 \\
\hline 5. Reconhecimento & $\begin{array}{l}\text { As pessoas são capazes de: desenvolvimento, } \\
\text { confiança e colaboração. }\end{array}$ & 16 & 12 & 08 & - & - & - \\
\hline $\begin{array}{l}\text { 6. Características orga-ni- } \\
\text { zacionais }\end{array}$ & $\begin{array}{l}\text { Atrair e reter pessoas de alto potencial e qualifi- } \\
\text { cação para o trabalho. }\end{array}$ & 05 & 08 & 02 & 11 & 04 & 06 \\
\hline $\begin{array}{l}\text { 7. Criação de condições } \\
\text { de trabalho }\end{array}$ & $\begin{array}{l}\text { Favoráveis à manutenção da motivação individu- } \\
\text { al para o trabalho; } \\
\text { Favoráveis à mobilização dos grupos em torno } \\
\text { das metas organizacionais. }\end{array}$ & 14 & 06 & 07 & 02 & 02 & 01 \\
\hline 8. Participação & $\begin{array}{l}\text { Estímulo à atitude de participação do emprega- } \\
\text { do. }\end{array}$ & 14 & 11 & 06 & 02 & 01 & 02 \\
\hline 9. Envolvimento & $\begin{array}{l}\text { Estímulo à atitude de envolvimento do emprega- } \\
\text { do com os objetivos organizacionais. }\end{array}$ & 16 & 11 & 05 & - & 01 & 03 \\
\hline 10. Comprometimento & $\begin{array}{l}\text { Estímulo à atitude de comprometimento (identi- } \\
\text { ficação) do empregado com os objetivos organi- } \\
\text { zacionais. }\end{array}$ & 13 & 10 & 05 & 03 & 02 & 03 \\
\hline 11. Expectativas & $\begin{array}{l}\text { Possibilidade de o empregado comunicar expec- } \\
\text { tativas em relação à unidade. } \\
\text { Ocorrência de comunicação das expectativas da } \\
\text { unidade em relação ao empregado. }\end{array}$ & 09 & 06 & 03 & 07 & 06 & 05 \\
\hline
\end{tabular}




\begin{tabular}{|c|c|c|c|c|c|c|c|}
\hline \multicolumn{8}{|c|}{$\begin{array}{l}\text { APRESENTAÇÃO DOS DADOS PARA A ANÁLISE DE CONTEÚDO } \\
\text { UNIDADES: IPIXUNA (I) MONTE DOURADO (MD) E BARCARENA (B) }\end{array}$} \\
\hline \multirow{3}{*}{$\begin{array}{l}\text { Unidades de Codificação } \\
\text { Palavras-tema }\end{array}$} & \multirow{3}{*}{ Palavras-chave ou Frases-chave } & \multicolumn{6}{|c|}{ Contagem } \\
\hline & & \multicolumn{3}{|c|}{ Presença } & \multicolumn{3}{|c|}{ Ausência } \\
\hline & & $\mathbf{I}$ & MD & B & $\mathbf{I}$ & MD & B \\
\hline 12. Responsabilidades & $\begin{array}{l}\text { Estímulo para o empregado assumir responsabili- } \\
\text { dades sobre suas ações. }\end{array}$ & 13 & 10 & 07 & 03 & 02 & 01 \\
\hline 13. Engajamento & $\begin{array}{l}\text { Estímulo ao engajamento das pessoas aos objeti- } \\
\text { vos e metas organizacionais. }\end{array}$ & 16 & 12 & 08 & - & - & - \\
\hline $\begin{array}{l}\text { 14. Características orga- } \\
\text { nizacionais }\end{array}$ & $\begin{array}{l}\text { Estimulando as pessoas a despenderem esforços } \\
\text { para nela permanecerem. }\end{array}$ & 06 & 09 & 04 & 10 & 03 & 04 \\
\hline \multirow{2}{*}{ 15. Cooperação } & \multirow{2}{*}{$\begin{array}{l}\text { Estímulo à atitude de cooperação; } \\
\text { Evidência da cooperação. }\end{array}$} & 12 & 10 & 06 & 04 & 02 & 02 \\
\hline & & 16 & 12 & 08 & - & - & - \\
\hline
\end{tabular}

Conforme se observa na tabela 1 , as unidades de codificação 1 a 7 se referem às palavras-tema contidas nas categorias de análise gestão estratégica de pessoas e estratégia de retenção de profissionais. Nessas categorias nota-se que:

Em Ipixuna as presenças são totalizadoras nas unidades de codificação 1 (frase-chave 2) e 5; quase totalizadoras nas 1 (frase-chave 1) e 7 (frase-chave 2). As ausências observadas nas unidades de codificação 2, 3, 4, 6 e 7 (frase-chave 1) denotam necessidade de investigação para a compreensão das razões, já que elas podem denotar visão desfavorável em relação aos aspectos nelas contidos.

Em Monte Dourado as presenças são totalizadoras nas unidades de codificação 1 (frasechave 2) e 5; quase totalizadoras nas 2, 3 e 7 (frase-chave 2). As ausências observadas nas unidades de codificação 1 (frase-chave 1), 4, 6 e, principalmente, 7 (frase-chave 1) já denotam necessidade de investigação;

Em Barcarena as presenças são totalizadoras nas unidades de codificação 1 (frase-chave 2) e 5; quase totalizadoras nas unidades de codificação 1 (frase-chave 1), 2, 3 e 7 (frasechave 2). As ausências observadas nas unidades de codificação 4, 6 (principalmente) e 7 (frase-chave 1) também denotam necessidade de investigação.

As unidades de codificação 8 a 15 estão voltadas para as palavras-tema contidas na categoria de análise comprometimento organizacional. Observa-se que:

Em Ipixuna a contagem de presenças é totalitária nas unidades de codificação 09, 13, e 15 (frase-chave 2) e expressiva nas unidades de codificação 8, 10, 12 e 15 (frase-chave 1) o que denota percepção positiva dos entrevistados, com relação aos aspectos do comprometimento nelas embutidos. As unidades de codificação 11 (em ambas as frases-chave) e 14 mostram que as ausências são significativas e necessitam de investigação;

Em Monte Dourado a contagem de presenças é totalitária nas unidades de codificação 13 e 15 (frase-chave 2) e expressiva nas unidades de codificação 8, 9, 10, 12, 13 e 15 (frase-chave 1), o que denota, também, percepção favorável dos entrevistados, com re- 
lação a esses aspectos. As unidades de codificação 11 (em ambas as frases-chave, mas, principalmente na 2) e 14 mostram que as ausências são significativas e necessitam de investigação;

Em Barcarena a contagem de presenças é totalitária nas unidades de codificação 13 e 15 (frase-chave 2); expressiva nas unidades de codificação 8, 11, 12 e 15 (frase-chave 1) e significativas nas unidades de codificação 9 e 10, o que denota favorabilidade, na percepção dos entrevistados. As unidades de codificação 11 (frase-chave2) e 14 (principalmente) mostram que as ausências são significativas e necessitam de investigação das razões que estão nelas embutidas.

\section{DISCUSSÃO DOS RESULTADOS}

Para analisar as características da gestão estratégica de pessoas, da estratégia de retenção de profissionais e da obtenção do comprometimento organizacional, toma-se por base o caso CADAM/PPSA, uma estrutura organizacional remota, confinada e isolada dos grandes centros urbanos, em toda a plenitude de suas peculiaridades.

São apresentados nos quadros 1 e 2 os resultados da análise de conteúdo aplicadada ao escopo da pesquisa, considerando que eles contribuem para aprofundar a compreensão do que foi mostrado na tabela 1 , principalmente pelo extrato das especificidades das unidades de análise oriundo dos conteúdos das entrevistas.

Ressalta-se que os temas significativos foram escolhidos pelo critério de categorização que englobasse todas as três unidades pesquisadas. As peculiaridades de cada uma dessas unidades de análise foram registradas como unidades de codificação. 
RESULTADO DA ANÁLISE DE CONTEÚDO APLICADO AO ESCOPO DA PESQUISA

UNIDADES DE ANÁLISE: IPIXUNA (I) MONTE DOURADO (MD) E BARCARENA (B)

\section{Tema Significativo}

Gestão Estratégica de Pessoas e Estratégia de Retenção de Profissionais /Per-

Categorias de Análise / cepção da adoção de novas práticas de gestão, de modo a facilitar a estratégia de retenção de profissionais e as ações de desenvolvimento e resolução de conflitos nessas organizações.

\section{Unidades de Codificação em Ipixuna (I)}

"Não há percepção de novas práticas de gestão no geral. Fica dependendo do diálogo de cada gestor, tanto no que diz respeito à forma de gestão que facilita o desenvolvimento, quanto no que se refere à resolução de conflitos".

"São adotadas novas práticas de gestão, mas elas precisam ser mais simples, de modo a impedir que o controle volte a ser excessivo".

"O incentivo à continuidade dos estudos é uma prática positiva".

"As equipes de melhorias contínuas são práticas facilitadoras e geram desenvolvimento".

"A resolução de conflitos é facilitada pelo diálogo entre os envolvidos. Por estarem confinadas, às vezes as pessoas agem sem pensar".

"O que é perceptível é que, tanto elogios quanto conversas a respeito do que há de bom na unidade estimulam as ações de desenvolvimento".

"A empresa poderia buscar novas formas de desenvolver as pessoas na unidade, de modo a diminuir conflitos hoje existentes entre as áreas, em meio à união das pessoas. A gestão pode aprimorar isso".

"As práticas adotadas de gestão, necessariamente precisam estar em linha com o desenvolvimento das pessoas e com a melhor forma de resolver os conflitos".

\section{Unidades de Codificação em Monte Dourado (MD)}

"A empresa tem se empenhado com novos modelos de gestão, de modo a criar desenvolvimento das pessoas e facilitar a resolução de conflitos".

"O relacionamento na unidade como um todo favorece a abertura para a minimização dos conflitos e diminuição de distâncias hierárquicas. As pessoas têm acesso ao gerente e aos outros níveis facilmente aqui dentro".

"Quando as pessoas são ouvidas pela estrutura hierárquica em relação aos resultados elas dão retornos expressivos para a unidade e para a organização".

"Esta estrutura só precisa lembrar que o trabalho é para as pessoas, com as pessoas e por intermédio delas. Se os gestores sabem como fazer isso o resultado é fantástico".

"As pessoas gostam de ser estimuladas e dão tudo de si quando assim se sentem".

"Nos últimos dez anos o apoio ao estudo tem gerado muito mais interesse pelo desenvolvimento pessoal e profissional". 


\section{Unidades de Codificação em Barcarena (B)}

“Os conflitos existem, até mesmo entre os pares de liderança. As práticas mediadoras de gestão facilitam".

"Há liberdade de adoção de práticas de facilitação em todas as circunstâncias na unidade. O processo de gerar feedback pode ser mais aprimorado. Falta ainda um pouco mais de humanização".

“A adoção de novas práticas de gestão tem se mostrado favorável, tanto para o desenvolvimento das pessoas quanto para a resolução de conflitos quando eles surgem na unidade".

"Para algumas pessoas a organização disponibiliza ações de desenvolvimento (principalmente para as que exercem funções de gestão). Para a resolução de conflito fica a cargo das áreas e dos gestores".

"A profissionalização é estimulada, o estudo é incentivado e as pessoas estão aderindo".

\section{Quadro 1}

Fonte: os autores, com base nos dados da pesquisa.

Os resultados ilustrados no quadro 1 são confrontados com a teoria, tomando-se por base: na categoria gestão estratégica de pessoas, estudiosos como Lengnick-Hall, Lengnick-Hall, Andrade e Drake (2009); Martín-Alcázar, Romeo-Fernández e Sánchez-Gardey (2008); Lepak e Shaw (2008); Martin-Alcázar; Romero-Fernández; Sanchez-Gardey (2005); Albuquerque e Leite (2009), Mascarenhas (2008), Lacombe e Albuquerque (2008); na categoria estratégia de retenção de profissionais, os autores Chew, (2004); Friedman, (2007).

Destacadamente, na categoria estratégia de retenção de profissionais, o estudo de Chew (2004) contribuiu por meio de elementos dos dois conjuntos de fatores que favorecem a prática de retenção de profissionais: fatores de gestão de pessoas (ajuste entre pessoas e organização, reconhecimento e recompensa, treinamento e desenvolvimento, oportunidades desafiadoras de trabalho); fatores organizacionais (atitude da liderança, políticas e cultura da organização, relacionamento entre integrantes da equipe de trabalho e ambiente de trabalho satisfatório). 
RESULTADO DA ANÁLISE DE CONTEÚDO APLICADO AO ESCOPO DA PESQUISA UNIDADES DE ANÁLISE: IPIXUNA (I) MONTE DOURADO (MD) E BARCARENA (B)

\begin{tabular}{l|l}
\hline $\begin{array}{l}\text { Categoria de Análise / } \\
\text { Tema Significativo }\end{array}$ & $\begin{array}{l}\text { Comprometimento Organizacional / } \\
\text { Percepção do orgulho e do empenho exercido pelos indivíduos em favor des- } \\
\text { sas organizações. }\end{array}$
\end{tabular}
sas organizações.

\section{Unidades de Codificação em Ipixuna (I)}

"O orgulho é muito grande, principalmente o de fazer acontecer os resultados".

"O orgulho de conseguir fazer as coisas planejadas é sempre evidenciado".

"Por vezes é difícil falar em orgulho quando a percepção de que a identidade organizacional é ambígua".

"O empenho é expresso nos resultados".

"Independentemente da idade, as pessoas se dedicam com orgulho e se empenham".

"O fato de estar fechado na estrutura remota faz com que as pessoas não se dispersem".

"As pessoas são verdadeiramente empenhadas com as suas atividades e demonstram orgulho com os resultados relevantes para a unidade e para a organização".

"O empenho existe e é repassado o exemplo para os subordinados acreditarem que eles podem".

"O empenho também está vinculado com o respeito pela empresa".

"Muitos são os exemplos de pessoas empenhadas que cresceram aqui dentro".

Unidades de Codificação em Monte Dourado (MD)

"Muitas pessoas sentem orgulho porque tiveram oportunidades. Outras não, daí fica muito relativo e a percepção, no geral, é que o orgulho é razoável".

"A maioria das pessoas na unidade procura desenvolver suas atividades profissionais de forma correta, não obstante estejam ou não, orgulhosas".

"As pessoas têm muito orgulho, apesar das dificuldades".

"O empenho é visível em recordes de produção e segurança".

"O empenho reforça os resultados, que por sua vez alimenta o orgulho de vestir a camisa".

"Algumas pessoas expressam o seu orgulho enfaticamente. As que vêm automotivadas engajam-se, estudam a distância e progridem". 


\section{Unidades de Codificação em Barcarena (B)}

"As pessoas demonstram o orgulho em trabalhar na unidade e, quanto mais se sentem valorizadas mais dão de si mesmas".

"As pessoas empenham-se constantemente em suas atribuições e trabalham na construção da obtenção dos resultados da unidade com muita dedicação".

"O comprometimento atesta o orgulho das pessoas, oriundo do trabalho com empenho, por elas realizado. As pessoas são verdadeiramente empenhadas com as suas atividades e demonstram o seu orgulho com os resultados relevantes para a unidade e para a organização".

"A harmonia do grupo está muito relacionada às suas interações dentro da unidade e na comunidade. Isso incrementa o empenho e o resultado é de alta performance".

“A valorização é um ponto-chave para o gestor. É importante passar o desafio e dizer para as pessoas o quanto elas são valiosas. O orgulho é oriundo da valorização que elas sentem".

“As pessoas são muito comprometidas. Quando as metas são lançadas, elas dão 'sangue' para atender. Elas demonstram seu orgulho junto com a alegria e o empenho".

\section{Quadro n. 2}

Fonte: os autores, com base nos dados da pesquisa.

Destaca-se que os resultados ilustrados no quadro 2 foram confrontados com os resultados obtidos com a teoria, tomando-se por base, na categoria comprometimento organizacional,os autores Salancik, 1977; Dessler, 1996; Walton, 1997; Albuquerque, 1999; Meyer, Stanley, Herscovitch, Topolnytsky, 2002; Moynihan, Pandey, 2007; Solinger, Olffen, Roe, 2008; Bastos, Siqueira, Medeiros, Menezes, 2008. Verifica-se, em cada unidade pesquisada, a presença de elementos teóricos dessa categoria.

Problematizando-se, na gestão estratégica de pessoas, a tradicional ênfase à estratégia de controle, caracterizada pela relação de troca não duradoura entre líder e liderado e inserindose, então, a perspectiva de lidar com a estratégia de comprometimento, por sua vez caracterizada pela articulação da experiência e dos significados compartilhados, pode-se verificar a estratégia de retenção viabilizando determinados modos de ação dos profissionais dessas organizações.

Como sugerido por Albuquerque (1999), em última instância, nota-se uma deliberação de mudança, em nível comportamental nessas organizações que, por suas especificidades, precisam realizar a mudança da estratégia de controle para a estratégia do comprometimento, em que, Walton (1997) deixou claro que a estratégia de controle representa um modelo de baixo comprometimento do profissional e, na de comprometimento, as mudanças são esperadas nas responsabilidades individuais, à medida que as condições mudam e, as equipes, não os indivíduos, se tornam as unidades organizacionais responsáveis pelo desempenho.

As características da gestão estratégica de pessoas na CADAM/PPSA, considerando-se a estratégia de retenção de profissionais e a obtenção do comprometimento organizacional em suas peculiaridades de estrutura organizacional remota na unidade de Ipixuna são assim definidas:

Por se tratar de uma unidade remota isolada e confinada, na maior parte do tempo a interação nessa unidade fica favorecida em função da convivência. As pessoas e os grupos acabam usufruindo aspectos da estrutura para o alcance dos resultados da unidade e das relações interpessoais. Fica registrado, o sentimento entre os entrevistados, de que as pessoas não estavam preparadas para a união das duas empresas e houve muito conflito. Há, também, o reconhecimento de um bom trabalho, promovido para que o momento dessa união pudesse ser entendido.

Os dados das entrevistas mostram que essa unidade aproxima as pessoas pela estrutura de moradia em alojamentos e as ações que denotam o orgulho surgem dessa aproximação. É reconhecido o fato de que estar em estrutura remota leva ao contato pessoal e pode influenciar no 
aumento do conhecimento de tudo o que é divulgado pela empresa, percebida como geradora de condições de crescimento e qualificação das pessoas, confrontações para resolver conflitos, sempre com a presença dos líderes das áreas envolvidas, o que leva à percepção de transparência das ações. Os empregados têm oportunidade de continuar seus estudos, graças ao Centro de Educação Continuada (CEC), desenvolvido dentro da unidade. A demanda por matrícula e a contagem de presenças às aulas têm sido consideradas excelentes nos últimos anos. No mesmo município, a empresa desenvolve, também, programas de educação ambiental, apoio à produção, à informática e às instituições de saúde.

Não obstante algumas ferramentas de gestão utilizadas no sentido de verificar pontos fortes e fracos, há a percepção de que falta aos gestores, o desenvolvimento das condições de utilização desses diagnósticos em prol da unidade. Para os entrevistados, a forma de gestão necessita ser o foco da preocupação. A expressão diária das ideias favorece a superação dos obstáculos, a implantação de melhorias e o alcance das metas pré-estabelecidas. $O$ empenho também está vinculado a essas questões. Os dados das entrevistas, no entanto, mostram a possibilidade do empenho ser oriundo do orgulho pessoal em fazer bem as atividades. Mostram, também, que a empresa quer elevar o orguIho, voltar aos níveis outrora existentes, mas, no momento atual, essa unidade não é determinante na obtenção do comprometimento organizacional. Esse empenho é percebido na forma com que as pessoas buscam o espaço para desenvolver o trabalho e criar condições de melhorias.

A estrutura é considerada sempre apoiadora. Contudo, é constatada pelos dados das entrevistas, falta de autonomia com relação ao processo decisório, centralizado na concentração gerencial em Barcarena e a distância física dos gestores é sentida pelas equipes de trabalho. Ainda de acordo com a opinião dos entrevistados, há comprometimento das pessoas para fazer com que a unidade aconteça e o negócio cresça. Elas sempre buscam soluções para os problemas. Para esses entrevistados, tais problemas que precisam ser resolvidos são de fácil solução, em razão do companheirismo existente. As pessoas não medem esforços e unem-se para que os objetivos possam ser alcançados.

As características da gestão estratégica de pessoas na CADAM/PPSA, considerando-se a estratégia de retenção de profissionais e a obtenção do comprometimento organizacional em suas peculiaridades de estrutura organizacional remota na unidade de Monte Dourado são assim definidas:

Os entrevistados afirmam que as mudanças para a vida, em unidade remota isolada e confinada, geram desconforto e uma série de comportamentos diferenciados. Assim, os modelos de gestão são olhados pelos representantes dessa unidade sob a ótica da adaptação das pessoas. As estruturas de Munguba, centro da unidade e de Monte Dourado, vila residencial, podem facilitar ou dificultar, pela mesma razão: a aproximação inevitável das pessoas em seu cotidiano. A privação de alguns aspectos da vida, no isolamento do remoto confinado é considerada relevante. Muitas vezes a unidade investe nessas pessoas e elas não permanecem por muito tempo. Por outro lado, a maioria das que ficam tem vínculos familiares fortes, pois escolhe conscientemente fugir dos grandes centros e criar os filhos em condições mais saudáveis. As que escolhem permanecer geram contribuições significativas, em função de suas habilidades (quer individuais, quer articuladas em grupos) serem utilizadas em prol dessa unidade. A política de gestão abrange visão, filosofia, missão e valores, de tal modo, que leva ao indivíduo a importância dos seus objetivos. Desde o treinamento introdutório o SIM - Sistema Integrado de Melhoria, fala-se de todas as coisas que o profissional precisa conhecer.

Há o reconhecimento de esforço na promoção de ações de desenvolvimento. Aos poucos, as pessoas vão internalizando e consolidando a essência dessa política. De acordo com os dados da pesquisa, há um cuidado especial em adotar práticas voltadas para o desenvolvimento 
das pessoas e para a resolução adequada dos conflitos nessa unidade. Os gestores estão sendo preparados para atuar melhor nessa direção. No entanto, o tempo proposto por esses gestores para permanência nessa unidade é percebido como curto para se desenvolver um trabalho consistente. O valor de residir em Monte Dourado é percebido como não internalizado por todos e, a distância é aumentada para a conquista do ideal de gestão. É enfatizado que os gestores que sentem prazer em morar no local da unidade interagem com as pessoas em todas as circunstâncias. Os que têm dificuldade de adaptação das famílias necessitam voltar para os seus locais de origem, o que representa muitas perdas. Essa circunstância já está sendo revista por alguns desses gestores.

As entrevistas atestam que as pessoas sentem orgulho por trabalhar na unidade e a vêem como um centro de excelência no meio da floresta. A empresa e os profissionais que nela trabalham são reconhecidos pelo mercado. Internamente, o orgulho é expresso nos diálogos de trabalho, nas conversas informais, nas ações de melhoria para os resultados. O empenho é confirmado pelo alto índice de obtenção desses resultados, notadamente os de produção, segurança e meio-ambiente. As pessoas não ficam atreladas somente aos treinamentos. Elas se empenham para que tudo corra bem. Esse empenho é percebido pelo esforço permanente de todos para atingir os objetivos. A estrutura é criada em função da preservação do bem-estar das pessoas, de modo a favorecer a retenção delas na unidade, mas não necessariamente eaas ação assegura que elas permaneçam. Somente a adaptação dessas pessoas e das suas famílias é que pode assegurar o maior tempo dessa permanência.

Os dados da pesquisa mostram que os sistemas estruturais e estruturantes da unidade facilitam as ações dos conflitos das pessoas no que tange às questões familiares e de trabalho. Entretanto, há a percepção entre esses entrevistados, de que as práticas de gestão precisam evoluir do plano operacional para o estratégico, com a compreensão que a retenção de profissionais talentosos é função de: salário digno, competência estimulada para ser incrementada e vontade de crescer mapeada e estimulada. A unidade é reconhecida como um bom lugar para se trabalhar e constitui-se sonho, de muitas pessoas da região, a ocupação de uma posição dentro dela. Os entrevistados salientam, ainda, que os resultados podem ser vistos como favoráveis e oriundos do grau de comprometimento das pessoas e, os sistemas criados, podem se ditos estimulantes.

As características da gestão estratégica de pessoas na CADAM / PPSA, considerando-se a estratégia de retenção de profissionais e de obtenção do comprometimento organizacional em suas peculiaridades de estrutura organizacional remota na unidade de Barcarena são assim definidas:

Os entrevistados enfatizam que os resultados nessa unidade são obtidos a partir da contribuição de todos. A estrutura vem contribuindo gradativamente com os resultados operacionais e, não obstante todas as mudanças oriundas de reestruturações, as pessoas sentem tal contribuição. Alguns gestores atendem às três unidades e essa é uma especificidade dessas organizações. Em algumas dessas unidades a periodicidade com que estão com a equipe é mensal. Esses gestores afirmam que se sentem tentados a desafiar constantemente os seus gerenciados para que eles possam decidir com base em suas convicções. Entretanto, há registro de que tais gerenciados se sentem inseguros com as ausências, apesar de lhes ser mostrado a valorização do seu trabalho. Para os entrevistados, ganha a unidade localizada mais próxima da residência dos gestores. Outros desses gestores moram na Vila dos Cabanos e reconhecem o valor que isso tem para as equipes em Barcarena.

As características dos gestores podem ser traduzidas nessa unidade em: flexibilidade, saber ouvir a equipe, facilitação na execução das tarefas com o compartilhamento da equipe, estímulo à co-responsabilidade, aprimoramento da prática de valorização das pessoas. Os documentos mostram que a área de recursos humanos na unidade era muito incipiente. Pouco a pouco foram implantadas as práticas que mostram o foco no desenvolvimento das pessoas e da 
própria unidade, nas quais as resoluções de conflitos são mediadas pelos gestores e acompanhadas, quando necessário, por profissionais de $\mathrm{RH}$.

Os gestores são ajudados pelo RH e pelos comitês multidisciplinares. A inexistência de barreira entre eles é também percebida como de grande ajuda na prática cotidiana, com abertura para ouvir e trocar. Ações como seminários fora, pessoas para fazer palestras dentro da unidade e treinamentos, facilitam o desenvolvimento. Isso tudo leva à transparência das ações, de acordo com os entrevistados.

Os dados da pesquisa mostram que as pessoas sentem orgulho em trabalhar nessa unidade, pois ela valoriza as qualificações que os empregados têm ou podem ter. Nesses dados, tem-se a seguinte distinção: as pessoas da área operacional mostram o seu orgulho na unidade, pelo fato de serem reconhecidas e prioritariamente contratadas na própria região; o orgulho é intensamente percebido nos veteranos; o sentimento de orgulho é desenvolvido e expresso, toda vez que um empregado terceirizado é contratado na unidade; dos cargos de analista para cima é dito que há comprometimento, mas o orgulho não é tão expresso e essas pessoas são recrutadas em Belém e em outras capitais.

$\mathrm{O}$ empenho existe e é verbalizado pelos empregados. Esse empenho também está vinculado ao respeito pela empresa. $\mathrm{O}$ orgulho torna-se mais visível e é traduzido pelos resultados positivos em prol da unidade. Não obstante a presença de outras empresas como ALBRAS e ALUNORTE, no mesmo pólo, que pode representar ameaça de absorção da mão-de-obra preparada, o empenho em realizar um trabalho de excelência nessa unidade é considerável e as pessoas não a deixam, segundo os entrevistados. Em Barcarena, os focos da empresa estão voltados, também, para a capacitação profissional e o aperfeiçoamento na área da produção, desenvolvidos em parceria com o Serviço Nacional de Aprendizagem Rural (SENAR). Atividades agrícolas, de pesca, avicultura e apicultura são oferecidas com intuito de promover e estimular a geração de trabalho e renda.

\section{CONSIDERAÇÕES FINAIS}

A gestão estratégica de pessoas, a estratégia de retenção de profissionais e o comprometimento organizacional em estruturas organizacionais localizadas fora dos grandes centros urbanos, nesta pesquisa, apresentaram, em características e peculiaridades de sua estrutura organizacional e nas interfaces das três unidades - Ipixuna, Monte Dourado e Barcarena, a existência de valores que levam à sinergia, à solidariedade e à confiança.

As semelhanças entre as três unidades mostraram traços que unem as pessoas, em todas essas localidades e em torno do mesmo propósito: reter profissionais de talento nas duas unidades com estruturas organizacionais remotas e na semi-remota. As diferenças entre essas unidades denotam aspectos, não obstante peculiares ligados à gestão estratégica de pessoas, à estratégia de retenção de profissionais e ao comprometimento organizacional, que mostram indícios de comprovação de relevância das bases teóricas utilizadas nesta pesquisa.

Pode-se dizer nessas unidades que, se torna possível identificar as peculiaridades que conduzem ao comprometimento das pessoas com os objetivos organizacionais, dentro de uma estrutura organizacional remota, a partir da abordagem estratégica da gestão de pessoas. Entretanto, a retenção de profissionais fica a cargo da capacidade de adaptação desses profissionais ou de seus familiares nessas regiões.

As políticas e as práticas de gestão de pessoas são oriundas da organização para as unidades de Barcarena, Ipixuna e Monte Dourado. Entretanto, há liberdade de ajustes em cada uma delas, quando e se necessário.

Os resultados aqui encontrados se referem ao caso, CADAM/PPSA e se acredita na contribuição desta pesquisa para novas investigações dentro de estruturas similares, distantes dos grandes centros urbanos, comparando-se estes resultados com outras unidades semi-remotas e não remotas. 


\section{REFERÊNCIAS}

ABBAGNANO, N. Dicionário de filosofia. São Paulo: Martins Fontes, 2003.

ALBUQUERQUE, L. G. Estratégias de recursos humanos e competitividade. In: VIEIRA, M. M. F.; Oliveira, L. M. B. (Orgs). Administração contemporânea: perspectivas e estratégias. São Paulo: Atlas, 1999.

ALBUQUERQUE, L. G. A gestão estratégica de pessoas. In: Fleury, M. T. L (Org). As pessoas na organização. São Paulo: Gente, 2002.

ALBURQUEQUE, L. G.; LEITE, N. P. Gestão de pessoas: perspectivas estratégicas. São Paulo: Atlas, 2009.

BARDIN, L. Análise de conteúdo. Lisboa: Edições 70, 2009.

BASTOS, A.V.B.;SIQUEIRA, M.M.M.; MEDEIROS, C. A. F.; MENEZES, I. G. Comprometimento organizacional. In: Siqueira, M. M. M. e Colaboradores. Medidas do comportamento organizacional: ferramentas de diagnóstico e de gestão. Porto Alegre: Artmed, 2008.

BECKER, B. E.; HUSELID, M. A. E ULRICH, D. Gestão estratégica de pessoas com scorecard: interligando pessoas, estratégia e performance. Rio de Janeiro: Campus, 2001.

CHEW, J. C. L. The influence of human resource management practices on the retention of core employees of Australian Organizations: an empirical study. Thesis (Doctor of Philosophy). Murdoch University, 2004.

COOPER, D. R.; SCHINDLER, P. S. Métodos de pesquisa em administração. Porto Alegre: Bookman, 2003.

DESSLER, G. Conquistando comprometimentocomo construir e manter uma força de trabalho competitiva. São Paulo: Makron Books, 1996.

EISENHARDT, K. M. Building theories from case study research. Academy of Management
Review, v. 14, n. 4, pp. 532-550, 1989.

EISENHARDT, K. M.; GRAEBNER, M. E. Theory building from cases: opportunities and challenges. Academy of Management Review, v. 50, n. 1, pp. 25-32, 2007.

FALKENBURG, K.; SCHYNS, B. Work satisfaction, organizational commitment and withdrawal behaviors. Management Research News, v. 30, n. 10, pp. 708-723, 2007.

FRIEDMAN, B. A. Globalization implications for human resource management roles. Employ Response Rights Journal, v. 19, pp. 157-171, 2007.

GIL, A. C. Estudo de caso. São Paulo: Atlas, 2009.

HANASHIRO, D. M. M.; TEIXEIRA, M. L. M.; ZACCARELLI, L. M. (Org) Gestão do fator humano: uma visão baseada em stakeholders. São Paulo: Saraiva, 2007.

LACOMBE, B. M. G.; AlbuQUerque, L. G. Avaliação e mensuração de resultados em gestão de pessoas: um estudo com as maiores empresas instaladas no Brasil. Revista de Administração da USP - RAUSP, v. 43, n.1, pp. 5-16, Jan./Mar. São Paulo: FEA/USP, 2008.

LEITE, N. R. P. Comprometimento e gestão de pessoas em empresas brasileiras com estruturas organizacionais remotas. São Paulo: FEA/USP. Tese de Doutorado em Administração, 2008.

LeITE, N. P.; ALBURQUeQUE, L. G. Políticas e práticas de gestão de pessoas: peculiaridades de uma estrutura organizacional remota. Revista de Administração da UFSM - ReA, v.2, n.2, pp. 370-394, Mai./Ago. Santa Maria: UFSM, 2009 a.

LEITE, N. P.; ALBURQUEQUE, L. G. Os desafios de gerir pessoas em uma estrutura organizacional remota. Revista de Gestão - REGE-USP, v.16, n. 3, pp. 81-96, Jul./Set. São Paulo: FEA/USP, 2009 b. 
LEITE, N. P.; ALBURQUEQUE, L. G. Gestão estratégica de pessoas: conceito, evolução e visão. In: Alburqueque, L. G.; Leite, N. P. Gestão de pessoas: perspectivas estratégicas, pp.3-16. São Paulo: Atlas, 2009 c.

LENGNICK-HALL, M. L.; LENGNICK-HALL, C. A.; ANDRAD, L. S.; DRAKE, B. Strategic human resource management: the evolution of the field. Human Resource Management Review, v. 19, n. 2, pp. 64-85, 2009.

LEPAK, D. P.; SHAW, J. D. Strategic HRM in North America: looking to the future. In: The International Journal of Human Resource Management, v. 19, n.8, pp. 1486-1499, 2008.

MARTÍN-ALCÁZAR, F.; ROMERO-FERNÁNDEZ, P. M.; SANCHEZ-GARDEY, G. Strategic human resource management: integrating the universalistic, contingent, configurational and contextual perspectives. The International Journal of Human Resource Management, v. 16, n. 5, pp. 633-659, 2005.

MARTÍN-ALCÁZAR, F.; ROMERO-FERNÁNDEZ, P. M.; SANCHEZ-GARDEY, G. Human resource management as a field of research. British Journal of Management, v. 19, pp. 103-119, 2008.

MASCARENHAS, A. O. Gestão estratégica de pessoas: evolução, teoria e crítica. São Paulo: Cengage Learning, 2008.

MATTOS, P. L. C. L. 'Os resultados de minha pesquisa qualitativa não podem ser generalizados: pondo os pingos nos is dessa ressalva'. Anais do XXX EnANPAD. Salvador: ANPAD, 2006.

MEYER, J. P.; STANLEY, J. D.; HERSCOVITCH, L.; TOPOLNYTSKY, L. Affective, Continuance, and Normative Commitment to the Organization: A Meta-analysis of Antecedents, Correlates, and Consequences. Journal of Vocational Behavior, v. 61, pp. 20-52, 2002.

MOWDAY, R. T.; PORTER, L. W.; STEERS, R. M Employee-organization linkages: the psychology of commitment, absenteeism, and turnover. New York: Academic Press, 1982.

MOYNIHAN, D. P.; PANDEY, S. K. Finding workable levers over work motivation: comparing job satisfaction, job involvement, and organizational commitment. Administration \& Society, v. 39, pp. 803-832, 2007.

PASCHINI, S. Estratégia: alinhando cultura organizacional e estratégia de RH à estratégia de negócio: a contribuição efetiva de RH para a competitividade do negócio. Rio de Janeiro: Qualitymark, 2006.

ROBBINS, S. P. Comportamento organizacional. São Paulo: Pearson / Prentice Hall, 2005.

ROGERS, C. R. Sobre o poder pessoal. São Paulo: Martins Fontes, 1977.

SALANCIK, G. R. Commitment and the control of organizational behavior and belief. In: Staw, B. M.; Salancik, G. R. (Ed) New direction in organizational behavior, pp. 1-54. Chicago: St.Clair, 1977.

SELLTIZ, C.; WRIGHTSMAN, L. S.; COOK, S. W. Métodos de pesquisa nas relações sociais. v. 2 - medidas na pesquisa social. São Paulo: EPU, 2005.

SOLINGER, O. N.; OLFFEN, W.; ROE, R. A. Beyond the three-component model of organizational commitment. Journal of Applied Psychology, v. 93, n. 1, pp. 70-83, 2008.

ULRICH, D. Os campeões de recursos humanos: inovando para obter os melhores resultados. São Paulo: Futura, 1998. Recursos humanos estratégicos. São Paulo: Futura, 2000.

ULRICH, D.; ULRICH, W. Por que trabalhamos: como grandes líderes constroem organizações comprometidas que vencem. Porto Alegre: Bookman, 2011.

ULRICH, D.; ALLEN, J.; BROCKBANK, W.; 
YOUNGER, J.; NYMAN, M. A transformação do $R H$ : construindo os recursos humanos de fora para dentro. Porto Alegre: Bookman, 2011.

WALTON, R. E.Docontrole ao comprometimento no local de trabalho. In: Gestão de pessoas, não de pessoal. Série Harvard business review book. Rio de Janeiro: Campus, pp. 95-112, 1997.

WRIGHT, P.; SNELL, S. Toward an integrative view of strategic human resource management. Human Resource Management Review, v.1. n. 3, pp. 203-225, 2001.

WRIGHT, P.; DUNFORD, B.; SNELL, S. Human resource and the resource based view of the firm. Journal of Management, v. 27, pp. 701721, 2001.

VERGARA, S. C. Métodos de pesquisa em administração. São Paulo: Atlas, 2005.

YIN, R. Estudo de caso: planejamento e métodos. São Paulo: Bookman, 2005. 